\title{
The Rasch Model Analysis for Statistical Anxiety Rating Scale (STARS)
}

\author{
Siti Mistima Maat, Mira Khalisa Rosli \\ Faculty of Education, The National University of Malaysia, Bangi, Selangor, Malaysia \\ Email: sitimistima@ukm.edu.my, mirakhalisarosli@gmail.com
}

How to cite this paper: Maat, S. M., \& Rosli, M. K. (2016). The Rasch Model Analysis for Statistical Anxiety Rating Scale (STARS). Creative Education, 7, 2820-2828. http://dx.doi.org/10.4236/ce.2016.718261

Received: November 7, 2016

Accepted: December 12, 2016

Published: December 15, 2016

Copyright $\odot 2016$ by authors and Scientific Research Publishing Inc. This work is licensed under the Creative Commons Attribution International License (CC BY 4.0).

http://creativecommons.org/licenses/by/4.0/

\begin{abstract}
The importance of statistics plays a growing role in research including students. The purpose of this study is to produce psychometric measurement using Rasch Model Analysis. 173 postgraduate students were chosen randomly to give response to 51 items of Statistical Anxiety Rating Scale (STARS). The collected data were analysed using SPSS and Winstep software. Based on the analysis, the person item and item reliability indicate 0.94 and 0.92 respectively. Item separation index for both person and item was more than the cut-off point of 2.00 which is considered good. The Rasch Model analysis has shown key aspects in learning statistics to be improvised.
\end{abstract}

\section{Keywords}

Statistical Anxiety, Rasch Model, Students, Postgraduates

\section{Introduction}

Statistics has been introduced to universities students since the 20th century (Arumugam, 2014) as the world nowadays needs Statistics to decipher information. The intention is to let the students understand the statistical concepts and be able to apply in real life situation. However, learning Statistics has become the greatest challenge among students at all levels of study. It has been recorded that the educators received students' feedback that shows their anxiety towards the Statistics course and decreasing students' performance in the course (Shah, Hamid, \& Sulaiman, 2014). Also, in Ashaari, Judi, and Mohamed (2011), the deterioration of students' attendance in class is really disturbing as it may affect their performance towards statistics. The difficulties in understanding statistics create barriers which give negative impact regardless of their field of study.

This relates to the existence of negative feelings towards statistics that can be defined 
as statistical anxiety which can occur when the students have to learn statistics (Schneider, 2011). Due to this negative perception, the students are not aware of the importance of Statistics (Keeley, Zayac, \& Correia, 2008). They even start to put off or avoid any task or assignments that relate to Statistics (Onwuegbuzie, 2004). This situation will dent the students' ability to learn and foster all the necessary skills in order to apply it to find data (Mcgrath, Greiner, Brown, Ferns, \& Wanamaker, 2015). Since statistics is related to mathematics, the students with weak mathematical background tend to struggle more in learning statistics (Shah et al., 2014).

There are a lot of ways to measure statistical anxiety, and Statistical Anxiety Rating Scale (STARS) is used widely in terms of observing the students' anxiety towards Statistics and helping the educator to find ways to curb this problem (Liu, Onwuegbuzie, \& Berks, 2011; Mcgrath et al., 2015). There are six major constructs in which four of the constructs focus on the context itself and the other two constructs are related to social issues (Williams, 2014). The constructs contained in STARS are interpretation anxiety, test and class anxiety, worth of statistics, computational self-concept, fear of asking for help and fear of statistics teachers. Interpretation anxiety is used to measure the students' anxiety regarding how they interpret the data given in journals; test and class anxiety will reflect their feelings when enrolling any Statistics classes including test and examination. Meanwhile the worth of statistics construct is used to see how the students valued the usefulness of statistics and computational self-concept reflects their own mathematical concept and applies the right analysis to interpret the result (Williams, 2014). Furthermore, fear of asking for help will access the student asking for help on understanding any statistical output, and fear of statistics teachers is how the students affect the statistics instructor.

Koh and Zawi (2014) found that there is no anxiety effect shown but the students experienced the highest score of anxiety in class activities while Shah et al. (2014) recorded a high level of anxiety and the highest score is found in fear of statistics teachers. Mcgrath et al. (2015) found that there is a non-significant negative correlation between anxiety and performance while a significant negative relationship between anxiety and self-efficacy which is consistent with Perepiczka, Becerra, and Chandler (2011) outcomes. However, there is a nonlinear correlation found in anxiety and performance (Keeley et al., 2008). Meanwhile, Sesé, Jiménez, Montaño, and Palmer’s (2015) finding indicates that the test anxiety is positively related to statistical anxiety through Structural Equation Modelling (SEM) method. Teman (2013) has done similar study on examining STARS using Rasch Model to 423 undergraduates and graduates. Somehow, a right dose of anxiety helps to elevate one's motivation by making them work smarter in learning and understanding statistics and eventually excel in the statistics course. Besides that, it seems that anxiety is affected by the students' achievement goal and motivation as found in Lavasani ${ }^{a}$ and Weisani (2013).

The study of statistical anxiety in students is crucial for the educators to program the curriculum that is accessible for the students without any hindrance through it. Substantial past studies have been done on statistical anxiety yet the focus on psychometric analysis is still limited. 
Therefore, the objective of this study is to determine the psychometric analysis of Statistical Anxiety Rating Scale (STARS) using the Rasch Model which include the following:

1) To determine the person and item reliability respectively;

2) To determine item separation index of person and item;

3) To identify the person and item measure respectively.

\section{Methodology}

This research used a survey research design for data collection purposes. Initially, 180 postgraduate students were chosen randomly to be the research's samples. However, based on SPSS analysis, 7 data were considered outliers and have to be removed from the original data. There were postgraduate students who enrolled in various fields of study such as Mathematics Education, Pre School programme, Malay Studies, Teaching English as Second Language (TESL) and so forth. The remaining data of 173 students was further analysed using Winstep in order to obtain the Rasch Model output. Majority of the respondents were female students which comprised of 135 (78\%) and the remaining were 38 (22\%) male students (Table 1 ).

Initially, STARS was developed by Cruise et al. with 89 items and after several analysis and varimax rotation, 51 items are interpretable (Baloğlu, 2002). The STARS used in this study was adapted from a previous study (Schneider, 2011) and the translation was done according to local research setting. Five point Likert scale was used which ranged from " 1 " as "Strongly disagree" to " 5 " as "Strongly agree". The consistency of the translation was done by language and content experts. Thirty minutes were given to the respondents in order to complete the questionnaire. Prior to Rasch model analysis, the STAR has gone through all the related assumptions that need to be fulfilled.

\section{Findings}

In this study, statistical anxiety is defined as latent trait which can be measured based on logit scores (Fisher, 1995). Based on the analysis using Rasch Model, Table 2 shows the output for person reliability and item separation index for 173 postgraduate students. The person reliability and item reliability were found to be rather high (Saidfudin et al., 2010) at 0.94 and 0.92 respectively. Any reliability value which is closed to 1 is considered consistent internally (Oon et al., 2016). This indicates that the items are supposedly measuring the statistical anxiety as required. While the separation index of 4.12 has exceeded the cut-off point of 2.0 as suggested by Fisher (2007). The person's separation index refers to the spread of all the respondents along a continuum

Table 1. Demographic profile.

\begin{tabular}{ccc}
\hline Gender & Frequency & $\%$ \\
\hline Male & 38 & 22.0 \\
Female & 135 & 78.0 \\
Total & 173 & 100.0 \\
\hline
\end{tabular}


Table 2. Person reliability and item separation index.

SUMMARY OF 173 MEASURED PERSON

\begin{tabular}{|c|c|c|c|c|c|c|c|c|c|c|}
\hline & \multirow{2}{*}{\multicolumn{2}{|c|}{$\begin{array}{l}\text { TOTAL } \\
\text { SCORE }\end{array}$}} & \multirow{2}{*}{ COUNT } & \multirow{2}{*}{ MEASURE } & \multirow{2}{*}{$\begin{array}{c}\text { MODEL } \\
\text { ERROR }\end{array}$} & \multicolumn{3}{|c|}{ INFIT } & \multicolumn{2}{|c|}{ OUTFIT } \\
\hline & & & & & & & MNSQ & ZSTD & MNSQ & ZSTD \\
\hline MEAN & \multicolumn{2}{|c|}{170.0} & 51.0 & 0.44 & 0.18 & & 1.03 & -0.9 & 1.02 & -0.9 \\
\hline S.D. & \multicolumn{2}{|c|}{27.7} & 0.0 & 0.95 & 0.04 & & 0.85 & 4.1 & 0.85 & 4.0 \\
\hline MAX. & \multicolumn{2}{|c|}{253.0} & 51.0 & 5.15 & 0.71 & & 4.54 & 9.9 & 4.43 & 9.9 \\
\hline MIN. & \multicolumn{2}{|c|}{107.0} & 51.0 & -1.37 & 0.16 & & 0.08 & -7.7 & 0.08 & -7.6 \\
\hline \multicolumn{3}{|c|}{ REAL RMSE $\quad 0.22$} & TRUE SD & \multicolumn{2}{|c|}{0.92 SEPARATION } & 4.12 & \multicolumn{4}{|c|}{2 PERSON RELIABILITY 0.94} \\
\hline \multicolumn{2}{|c|}{ MODEL RMSE } & 0.19 & TRUE SD & \multicolumn{2}{|c|}{0.93 SEPARATION } & 4.95 & \multicolumn{4}{|c|}{ PERSON RELIABILITY 0.96} \\
\hline \multicolumn{11}{|c|}{ S.E. OF PERSON MEAN $=0.07$} \\
\hline
\end{tabular}

Table 3. Item reliability and item separation index.

SUMMARY OF 51 MEASURED ITEM

\begin{tabular}{|c|c|c|c|c|c|c|c|c|c|c|}
\hline & \multirow{2}{*}{\multicolumn{2}{|c|}{$\begin{array}{l}\text { TOTAL } \\
\text { SCORE }\end{array}$}} & \multirow{2}{*}{ COUNT } & \multirow{2}{*}{ MEASURE } & \multirow{2}{*}{$\begin{array}{l}\text { MODEL } \\
\text { ERROR }\end{array}$} & \multicolumn{3}{|c|}{ INFIT } & \multicolumn{2}{|c|}{ OUTFIT } \\
\hline & & & & & & & MNSQ & ZSTD & MNSQ & ZSTD \\
\hline MEAN & \multicolumn{2}{|c|}{576.8} & 173.0 & 0.00 & 0.10 & & 1.00 & -0.1 & 1.02 & 0.1 \\
\hline S.D. & \multicolumn{2}{|c|}{42.1} & 0.0 & 0.35 & 0.01 & & 0.18 & 1.6 & 0.24 & 1.9 \\
\hline MAX. & \multicolumn{2}{|c|}{696.0} & 173.0 & 0.81 & 0.12 & & 1.60 & 5.3 & 1.85 & 6.8 \\
\hline MIN. & \multicolumn{2}{|c|}{474.0} & 173.0 & -0.83 & 0.08 & & 0.74 & -2.6 & 0.72 & -2.6 \\
\hline \multicolumn{3}{|c|}{ REAL RMSE $\quad 0.10$} & TRUE SD & \multicolumn{2}{|c|}{0.33 SEPARATION } & \multicolumn{4}{|c|}{3.29 ITEM RELIABILITY } & 0.92 \\
\hline \multicolumn{2}{|c|}{ MODEL RMSE } & 0.10 & TRUE SD & 0.33 SEPA & ATION & 3.41 & 1 ITEN & RELIAB & ITY & 0.92 \\
\hline \multicolumn{6}{|c|}{ S.E. OF ITEM MEAN $=0.05$} & & & & & \\
\hline
\end{tabular}

line based on an agreeable aspect. There were four distinguished group of respondents based on their anxiety level towards statistics.

Next, Table 3 shows the summary of 51 measured items for STARS. The item reliability was found at a good rate of 0.92 with separation index of 3.41. The item separation spread the items along the interval scale. Any low value for item separation indicates poor item division which is low reliability value. To overcome this issue, more respondents are required so that the reliability value could be increased. Both values were fit with the requirement for good measurement. The high item reliability value indicates high consistency in estimating the construct. It has a high probability value in the statistical anxiety measure which is due to the number of samples. As the sample increases, the reliability value increases which indicates that the instrument is stable (Arasinah, Bakar, Ramlah, Soaib, \& Zaliza, 2015). Oon et al. (2016) suggested to add more items in order to have good measure in the dimension for the item separation index.

Positive point measure correlation of all STARS items is shown in Table 3 which indicates to attend content validity. The values are ranging from 0.34 to 0.68 which meets the cut of point of more than 0.30 as suggested by Smith (2003) which is illustrated by the values in the red box.

Next, the item fit statistics for person is also shown in Table 4. Both person and 
items fit are considered the same which applies the equivalent fit criteria (Bond \& Fox, 2015). The INFIT describes the performance which is based on the samples' responses (Oon et al., 2016). In addition, the OUTFIT represents the unweighted score for the unexpected item behaviour which is beyond the samples' responses. The suggested Infit mean square (INFIT MNSQ) and Outfit mean square (OUTFIT MNSQ) values should be between 0.72 to 1.30 logits which implies $t$ values in the range of -2 to +2 (Bond \& Fox, 2015). As such, the Infit values 0.79 to 1.60 with their $t$ values ranging from -2.3 to 5.3. The outlier person was shown by the $32^{\text {nd }}$ respondent which indicates Infit value of 1.60 of $t$ value 5.3. While the Outfit value which ranging from 0.72 to 1.85 and $t$ value is between -2.6 to 6.8 . The outlier is shown by $25^{\text {th }}$ and $32^{\text {nd }}$ respondents. Items $\# 32$, \#17, \#46, \#18 \& \#15 are highlighted in yellow which are categorized as misfitting items. Further investigation on the respondents of those items is needed to be done in order to identify some anticipated problems. However, the values conclude that the items were measured in the same direction.

Based on Person-Map Item figure as shown in Figure 1, the vertical dash separates the person and the items. The symbol of \# represents the frequency of the respondents. Each symbol represents two respondents. The respondents are also ranked based on

Table 4. Item measure for STARS.

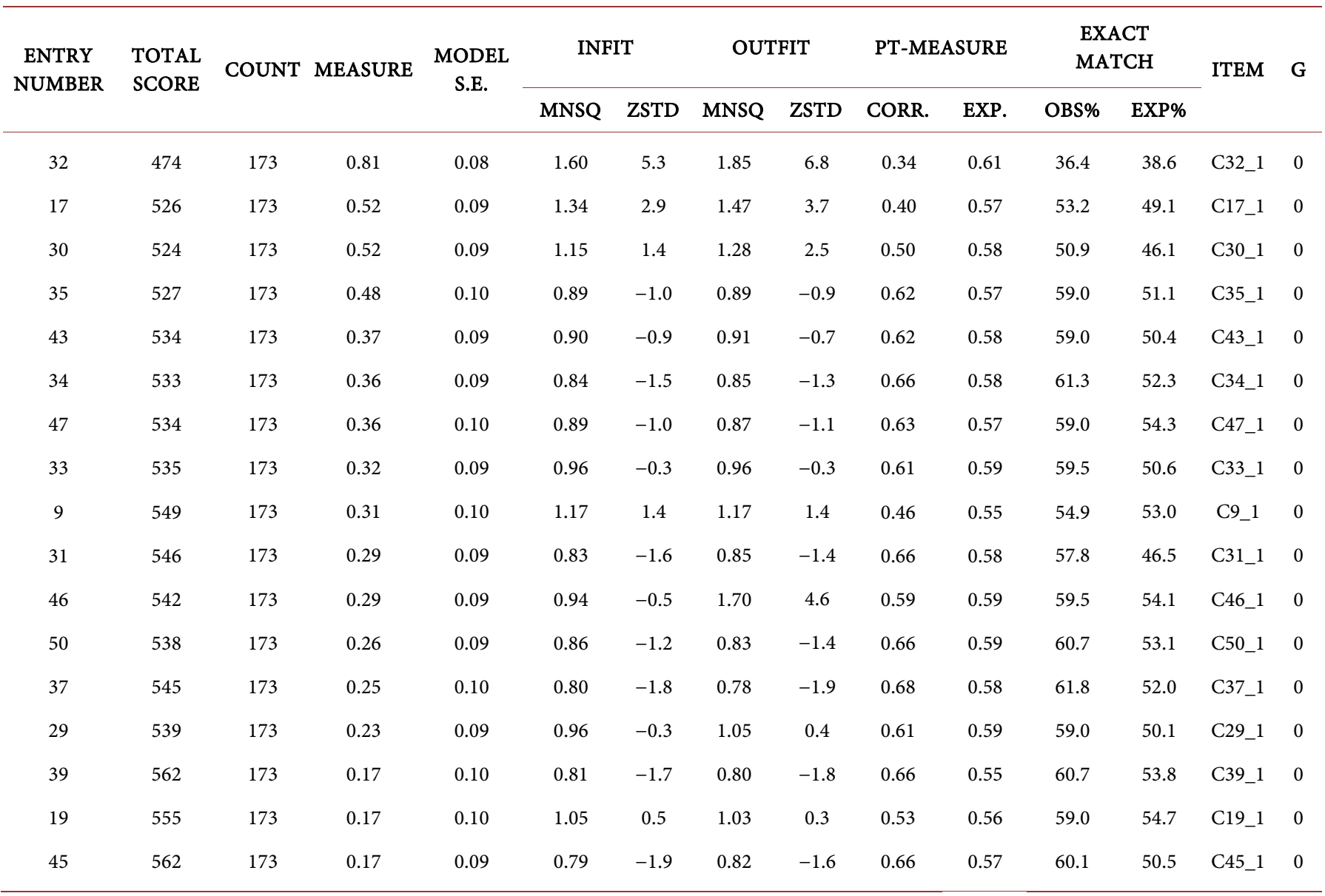




\section{Continued}

\begin{tabular}{|c|c|c|c|c|c|c|c|c|c|c|c|c|c|c|}
\hline 49 & 564 & 173 & 0.16 & 0.10 & 0.78 & -1.9 & 0.74 & -2.1 & 0.68 & 0.56 & 63.0 & 56.4 & C49_1 & 0 \\
\hline 24 & 569 & 173 & 0.15 & 0.09 & 1.04 & 0.4 & 1.10 & 0.8 & 0.54 & 0.56 & 57.2 & 51.4 & C24_1 & 0 \\
\hline 18 & 560 & 173 & 0.13 & 0.10 & 1.24 & 2.1 & 1.38 & 3.1 & 0.43 & 0.56 & 54.9 & 49.7 & C18_1 & 0 \\
\hline 3 & 575 & 173 & 0.11 & 0.10 & 1.22 & 1.8 & 1.28 & 2.2 & 0.42 & 0.54 & 53.8 & 51.9 & C3_1 & 0 \\
\hline 41 & 563 & 173 & 0.11 & 0.10 & 0.84 & -1.4 & 0.81 & -1.6 & 0.66 & 0.57 & 59.5 & 53.6 & C41_1 & 0 \\
\hline 16 & 563 & 173 & 0.11 & 0.10 & 1.28 & 2.3 & 1.26 & 2.1 & 0.42 & 0.57 & 49.1 & 51.6 & C16_1 & 0 \\
\hline 48 & 573 & 173 & 0.11 & 0.10 & 0.93 & -.6 & 0.91 & -0.7 & 0.60 & 0.56 & 63.6 & 57.7 & C48_1 & 0 \\
\hline 42 & 555 & 173 & 0.10 & 0.09 & 0.85 & -1.4 & 0.85 & -1.2 & 0.66 & 0.58 & 61.3 & 51.5 & C42_1 & 0 \\
\hline 14 & 580 & 173 & 0.10 & 0.09 & 1.14 & 1.2 & 1.22 & 1.8 & 0.48 & 0.55 & 58.4 & 48.4 & C14_1 & 0 \\
\hline 40 & 576 & 173 & 0.07 & 0.09 & 0.86 & -1.3 & 0.87 & -1.1 & 0.63 & 0.57 & 57.2 & 47.5 & C40_1 & 0 \\
\hline 51 & 570 & 173 & 0.05 & 0.09 & 1.02 & 0.2 & 1.08 & 0.7 & 0.57 & 0.58 & 54.9 & 52.3 & C51_1 & 0 \\
\hline 38 & 565 & 173 & 0.03 & 0.10 & 0.78 & -2.2 & 0.76 & -2.3 & 0.69 & 0.57 & 57.2 & 49.8 & C38_1 & 0 \\
\hline 36 & 573 & 173 & 0.03 & 0.09 & 0.89 & -1.0 & 0.97 & -0.2 & 0.62 & 0.57 & 59.0 & 48.0 & C36_1 & 0 \\
\hline 44 & 569 & 173 & 0.02 & 0.10 & 0.94 & -0.5 & 0.91 & -0.7 & 0.60 & 0.57 & 60.1 & 52.8 & C44_1 & 0 \\
\hline 27 & 581 & 173 & 0.00 & 0.09 & 0.76 & -2.3 & 0.73 & -2.5 & 0.69 & 0.57 & 60.1 & 48.1 & C27_1 & 0 \\
\hline 12 & 576 & 173 & -0.01 & 0.11 & 1.04 & 0.4 & 1.04 & 0.3 & 0.52 & 0.54 & 56.6 & 53.3 & C12_1 & 0 \\
\hline 6 & 586 & 173 & -0.07 & 0.11 & 1.24 & 1.9 & 1.25 & 2.0 & 0.39 & 0.54 & 56.1 & 54.0 & C6_1 & 0 \\
\hline 26 & 596 & 173 & -0.19 & 0.10 & 0.81 & -1.8 & 0.79 & -1.9 & 0.66 & 0.56 & 58.4 & 49.3 & C26_1 & 0 \\
\hline 11 & 597 & 173 & -0.23 & 0.11 & 0.91 & -0.8 & 0.88 & -0.9 & 0.59 & 0.54 & 61.3 & 55.5 & C11_1 & 0 \\
\hline 5 & 588 & 173 & -0.24 & 0.10 & 0.99 & -0.1 & 0.96 & -0.3 & 0.56 & 0.55 & 60.7 & 52.3 & C5_1 & 0 \\
\hline 13 & 612 & 173 & -0.30 & 0.10 & 1.23 & 2.0 & 1.30 & 2.6 & 0.39 & 0.53 & 48.6 & 48.5 & C13_1 & 0 \\
\hline 25 & 623 & 173 & -0.32 & 0.09 & 0.74 & -2.6 & 0.72 & -2.6 & 0.68 & 0.54 & 53.8 & 46.6 & C25_1 & 0 \\
\hline 20 & 591 & 173 & -0.32 & 0.11 & 1.13 & 1.1 & 1.12 & 1.0 & 0.47 & 0.54 & 60.7 & 53.3 & C20_1 & 0 \\
\hline 4 & 617 & 173 & -0.34 & 0.10 & 1.09 & 0.8 & 1.11 & 0.9 & 0.47 & 0.53 & 50.9 & 50.3 & C4_1 & 0 \\
\hline 21 & 599 & 173 & -0.34 & 0.10 & 1.02 & 0.3 & 0.99 & -0.1 & 0.55 & 0.56 & 60.1 & 50.8 & C21_1 & 0 \\
\hline 22 & 619 & 173 & -0.36 & 0.09 & 0.96 & -0.3 & 0.91 & -0.7 & 0.58 & 0.55 & 52.0 & 46.0 & C22_1 & 0 \\
\hline 10 & 612 & 173 & -0.37 & 0.11 & 1.01 & 0.1 & 1.02 & 0.2 & 0.52 & 0.52 & 54.9 & 50.9 & C10_1 & 0 \\
\hline 15 & 663 & 173 & -0.39 & 0.08 & 1.33 & 2.7 & 1.41 & 2.7 & 0.41 & 0.52 & 53.2 & 43.0 & C15_1 & 0 \\
\hline 7 & 619 & 173 & -0.47 & 0.12 & 1.18 & 1.5 & 1.18 & 1.5 & 0.37 & 0.49 & 54.9 & 54.4 & C7_1 & 0 \\
\hline 23 & 588 & 173 & -0.49 & 0.11 & 0.91 & -0.8 & 0.89 & -0.9 & 0.60 & 0.55 & 65.9 & 57.0 & C23_1 & 0 \\
\hline 8 & 696 & 173 & -0.56 & 0.11 & 1.13 & 1.3 & 1.06 & 0.6 & 0.42 & 0.48 & 45.7 & 51.3 & C8_1 & 0 \\
\hline 2 & 658 & 173 & -0.65 & 0.10 & 0.98 & -0.1 & 0.94 & -0.5 & 0.52 & 0.50 & 46.2 & 50.6 & C2_1 & 0 \\
\hline 28 & 627 & 173 & -0.71 & 0.10 & 0.82 & -1.8 & 0.80 & -2.0 & 0.64 & 0.53 & 60.1 & 47.8 & C28_1 & 0 \\
\hline 1 & 690 & 173 & -0.83 & 0.10 & 0.97 & -0.2 & 0.87 & -1.0 & 0.53 & 0.49 & 48.0 & 48.8 & C1_1 & 0 \\
\hline MEAN & 576.8 & 173.0 & 0.00 & 0.10 & 1.00 & -0.1 & 1.02 & 0.1 & & & 56.6 & 50.9 & & \\
\hline S.D. & 42.1 & 0.0 & 0.35 & 0.01 & 0.18 & 1.6 & 0.24 & 1.9 & & & 5.3 & 3.4 & & \\
\hline
\end{tabular}




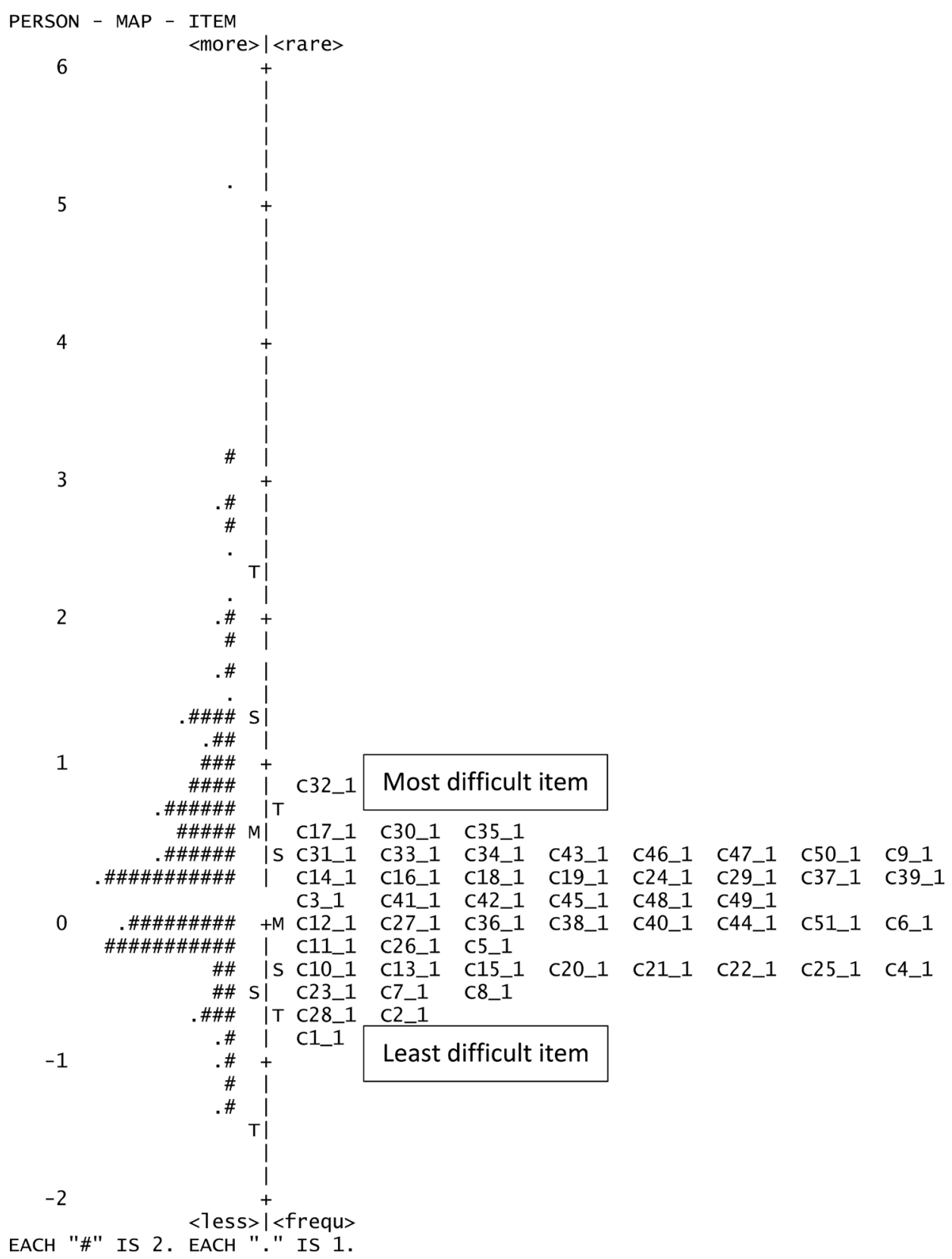

Figure 1. Person map item.

their ability. The lower part is for respondents with low ability and the top is for those respondents with high ability. The items of STARS are placed on the right side of the line and are sorted accordingly. The easiest items are placed at the bottom and gradually the most difficult items are on the top. Item C32 refers to statement of "Most statistics teachers are not human" which is considered the most difficult item among all the STARS items. While item C1 of "Studying for an examination in a statistics course" is easy to be agreed by all the respondents.

The distribution of persons in this study does not match with the item distribution. Most items are overlapping with the others which are measuring the same underlying 
constructs. For instance, C28 of "Statistics takes more time than it's worth." and C2 of "Interpreting the meaning of a table in a journal article" are considered as a single construct. Both items are categorized as easy items. Indirectly, this figure provides the information on discrimination for item difficulty and person ability respectively.

\section{Conclusion}

The lack of statistical evidence of STARS has prompted this study. This research presents psychometric characteristics for STARS which aims at profiling postgraduate students based on their statistical anxiety responses. Based on the Rasch model analysis, it provides the evidence that the STARS is acceptable to be used in determining the anxiety level among students and beneficial to the educators in accessing student's anxiety. Teman (2013) suggested that altering the words and rebuilding the items can help increase the efficiency of this instrument. The STARS has been evaluated psychometrically that can be used in future works particularly in replicating the study. Other aspects in Rasch Model analysis can be taken into consideration including differential item functioning for future research.

\section{Acknowledgements}

This research was supported by Geran Penyelidik Muda at the National University of Malaysia (GGPM2015-031).

\section{References}

Arasinah, K., Bakar, A. R., Ramlah, H., Soaib, A., \& Zaliza, H. (2015). Using Rasch Model and Confirmatory Factor Analysis to Assess Instrument for Clothing Fashion Design Competency,. International Journal of Social Science and Humanity, 5, 418-421. https://doi.org/10.7763/IJSSH.2015.V5.492

Arumugam, R. N. (2014). Student's Attitude towards Introductory Statistics Course at Public Universities Using Partial Least Square Analysis. Interdisciplinary Journal of Cotemporary Research in Business, 6, 94-123.

Ashaari, N. S., Judi, H. M., \& Mohamed, H. (2011). Student's Attitude towards Statistics Course. Procedia-Social and Behavioral Sciences, 18, 287-294. https://doi.org/10.1016/j.sbspro.2011.05.041

Bond, T. G., \& Fox, C. M. (2015). Applying the Rasch Model: Fundamental Measurement in the Human Sciences (3rd ed.). Mahwah, NJ: L. Erlbaum.

Fisher, G. (1995). Derivations of the Rasch Model. In G. H. Fisher, \& I. W. Molenaar (Eds.), Rasch Models: Foundations Recent Developments and Applications (pp. 15-38). Berlin: Springer-Verlag. https://doi.org/10.1007/978-1-4612-4230-7

Fisher, W. P. (2007). Rating Scale Instrument Quality Criteria. Rasch Measurement Transactions, 21, 1095.

Baloğlu, M. (2002). Psychometric Properties of the Statistics Anxiety Rating Scale. Psychological Reports, 90, 315-325. https://doi.org/10.2466/pr0.2002.90.1.315

Keeley, J., Zayac, R., \& Correia, C. (2008). Curvilinear Relationships between Statistics Anxiety and Performance among Undergraduate Students: Evidence for Optimal Anxiety. Statistic Education Research Journal, 7, 4-15. 
Koh, D., \& Zawi, M. K. (2014). Statistics Anxiety among Postgraduate Students. International Education Studies, 7, 166-174. https://doi.org/10.5539/ies.v7n13p166

Lavasani, M. G., \& Weisani, M. (2013). Statistics Anxiety, Achievement Goals, and Academic Motivation. Global Journal of Science, Engineering and Technology, No. 5, 61-77.

Liu, S., Onwuegbuzie, A. J., \& Berks, P. S. (2011). Examination of the Score Reliability and Validity of the Statistics Anxiety Rating Scale in a Chinese Population: Comparisons of Statistics Anxiety between Chinese College Students and Their Western Counterparts. Journal of Educational Enquiry, 11, 29-42.

Mcgrath, A. L., Greiner, L., Brown, S., Ferns, A., \& Wanamaker, K. (2015). Reducing Anxiety and Increasing Self-Efficacy within an Advanced Graduate Psychology Statistics Course. The Canadian Journal for the Scholarship of Teaching and Learning, 6, 1-17. https://doi.org/10.5206/cjsotl-rcacea.2015.1.5

Onwuegbuzie, A. J. (2004). Academic Procrastination and Statistics Anxiety. Assessment \& Evaluation in Higher Education, 29, 3-19. https://doi.org/10.1080/0260293042000160384

Perepiczka, M., Becerra, M., \& Chandler, N. (2011). Relationship between Graduate Students' Statistics Self-Efficacy, Statistics Anxiety, Attitude toward Statistics, and Social Support. The Professional Counselor, 1, 99-108. https://doi.org/10.15241/mpa.1.2.99

Oon, P.-T., Spencer, B., \& Kam, C. C. S. (2016). Psychometric Quality of a Student Evaluation Teaching Survey in Higher Education. Assessment \& Evaluation in Higher Education, 1-13.

Saidfudin, M., Azrilah, A., Rodzo'an, N., Omar, M., Zaharim, A., \& Basri, H. (2010). Easier Learning Outcomes Analysis Using Rasch Model in Engineering Education Research. Latest Trends on Engineering Education, 442-447. http://www.wseas.us/e-library/conferences/2010/Corfu/EDUCATION/EDUCATION-77.pdf

Schneider, W. R. (2011). The Relationship between Statistics Self-Efficacy, Statistics Anxiety, and Performance in an Introductory Graduate Statistics Course. PhD Theses and Dissertations, Tampa: University of South Florida.

Smith, R. M. (2003). Rasch Measurement Models: Interpret in WINSTEPS/BIGSTEPS and FACETS Output. Maple Grove: JAM Press.

Sesé, A., Jiménez, R., Montaño, J., \& Palmer, A. (2015). Can Attitudes toward Statistics and Statistics Anxiety Explain Students "Performance"? Journal of Psychodidactics, 20, 285-304. https://doi.org/10.1387/RevPsicodidact.13080

Shah, H., Hamid, A., \& Sulaiman, M. K. (2014). Statistics Anxiety and Achievement in a Statistics Course among Psychology Students. International Journal of Behavioral Science, 9, 55-66.

Teman, E. D. (2013). A Rasch Analysis of the Statistical Anxiety Rating Scale. Journal of Applied Measurement, 14, 414-434.

Williams, A. (2014). An Exploration of Preference for Numerical Information in Relation to Math Self-Concept and Statistics Anxiety in a Graduate Statistics Course. Journal of Statistics Education, 22, 1-16. 
Submit or recommend next manuscript to SCIRP and we will provide best service for you:

Accepting pre-submission inquiries through Email, Facebook, LinkedIn, Twitter, etc.

A wide selection of journals (inclusive of 9 subjects, more than 200 journals)

Providing 24-hour high-quality service

User-friendly online submission system

Fair and swift peer-review system

Efficient typesetting and proofreading procedure

Display of the result of downloads and visits, as well as the number of cited articles

Maximum dissemination of your research work

Submit your manuscript at: http://papersubmission.scirp.org/

Or contact ce@scirp.org 